Article

\title{
Development of an Occupational Health Safe Return to Work Prototype Application and Ergonomics Dataset for Agricultural Tasks
}

\author{
Bryan Weichelt ${ }^{1, *(\mathbb{D}}$, William Ray ${ }^{2}$ and Matthew Keifer ${ }^{3}$ \\ 1 National Farm Medicine Center, Marshfield Clinic Research Institute (MCRI), Marshfield, WI 54449, USA \\ 2 Readify, Sydney 2010, Australia; willray@outlook.com \\ 3 University of Washington and Puget Sound Veterans Administration, Seattle, WA 98108, USA; \\ Matthew.Keifer@va.gov \\ * Correspondence: weichelt.bryan@marshfieldresearch.org or weichelt.bryan@mcrf.mfldclin.edu
}

Received: 14 March 2019; Accepted: 4 June 2019; Published: 17 June 2019

\begin{abstract}
Serious, restrictive, non-fatal injuries are commonplace in large animal agriculture including in pork and dairy production. Primary care clinicians often have few resources to facilitate workers' return to work and have difficulties communicating work restrictions/limitations to workers and their employers. This project developed SafeReturnToWork.org, a web-based platform to aid physicians and farmers in farmworkers' timely and safe return to work. This prototype characterizes the duties of dairy and pork workers, and facilitates the creation of applicable light duty job assemblies for farmers and farmworkers by physicians and other healthcare providers. Guided by interviews and focus groups with physicians, farmers, and farmworkers, the system was developed for use with workplace injuries that could eventually link to human resource department systems, an electronic health record, or expand to other industries beyond agriculture.
\end{abstract}

Keywords: occupation; injury; return to work; farmer; farmworker; agriculture; ergonomics

\section{Introduction}

Farming is an inherently dangerous industry. The agricultural, forestry, and fishing, hunting, and trapping industries account for nearly $30 \%$ of the total economic cost for workplace injuries. Grouped together under agriculture, it is considered the most dangerous industry sector in the United States [1,2]. Leigh et al. note that the number of non-fatal injuries in agriculture is much higher than reported due to logistical shortcomings and underreporting in the measurements used to track workplace injuries in this industry [1]. Based on current reporting methods for workplace injuries, livestock handling is the largest contributor to workplace injury in the agricultural industry worldwide [3].

Farming operations continue to expand and diversify. In the Wisconsin dairy industry for example, herd sizes and total production have been increasing for decades [4]. To keep pace with production needs, farmers hire more workers that are generally from other countries, do not have a high level of education and/or experience communicating in the English language, and may not have previous livestock handling experience [5]. According to Liebman et al. [5], between $40 \%$ and $60 \%$ of all dairy workers in Wisconsin are from Hispanic countries and have limited experience with livestock handling. Any training these workers receive is generally on-the-job, and this training may not thoroughly cover topics in workplace safety or be in a format that is easily understandable for non-native English speakers [5]. Aside from language and cultural barriers, many farmers also lack the time, knowledge, and skill set to properly train their workers about occupational safety [6,7]. This lack of knowledge, combined with inherent communication difficulties between the farmer and his/her workers, not only 
increases a farm's risk for occupational injuries but also raises many issues when an individual does get injured on the farm.

Primary care physicians play an important role in the treatment and rehabilitation of injured workers. They treat the initial injury, develop a rehabilitation plan, and serve as a liaison between the injured worker, the worker's employer, and insurance companies (depending on whether or not the employer provides workers' compensation insurance to their employees), a role for which many physicians are ill-equipped. In addition to the unfortunate gap of many electronic health record systems' lacking occupational information [8], clinicians are often unfamiliar with the physical demands of farming, and they have little training and few resources to manage the return-to-work/rehabilitation plan of injured workers. Medical school does little to prepare physicians to effectively play the role of a return-to-work supervisor with injured patients [9]. Yet, physicians are generally called upon by insurance companies to: (1) complete paperwork pertaining to workers' compensation, (2) inform the worker and the employer regarding work restrictions, and (3) periodically evaluate the injured worker to determine whether or not he/she is eligible for additional coverage from the workers' compensation insurance source [10]. These extraneous roles are oftentimes detrimental to the physician-patient relationship and are a source of stress and vexation for many physicians, as they do not receive payment for the additional paperwork or evaluations relating to workers' compensation $[9,10]$. Furthermore, insurance companies may disagree with the physician's recommendations and refuse to provide coverage and/or benefits for the prescribed treatment [10]. However, as many agricultural workers generally do not have workers' compensation insurance, the major challenge for physicians involved in the treatment of agricultural injuries is to effectively communicate with the worker and his/her employer regarding restrictions/limitations on various physical tasks. Physicians, as well as physical and occupational therapists, record narrative data for these cases and utilize pre-existing workers' compensation forms, which are not in a format conducive to efficient use by the farmworker and his/her employer. Furthermore, these forms make it particularly difficult for others, such as insurance companies, to measure and track various trends with respect to injury management. In many cases, employers decide that it is better for the worker to stay at home until they have completely healed rather than provide light duty job tasks for the individual during the recovery period [11].

To overcome these communication barriers among healthcare providers, farmers/farm owners, and farmworkers regarding injury prevention and injury mitigation with respect to insurance (workers' compensation and other plans) for agricultural workers, a team of researchers in the Upper Midwest developed a system dubbed "Safe Return to Work" [12]. This paper will describe the development of the project, specifically the collection and integration of ergonomic data.

\section{Materials and Methods}

An electronic database of ergonomic tasks performed by agricultural workers was developed by a team of representatives from the Professional Dairy Producers of Wisconsin (PDPW) and Pork Board (professional organizations for the dairy and pork industries), the National Farm Medicine Center Dairy Safety Advisor, as well as clinicians, occupational therapists, usability analysts, programmers, applications analysts, and researchers from the Marshfield Clinic Research Institute.

Data collection efforts included worksite visits to collect and categorize worker tasks by ergonomic, injury, and exposure hazards as well as the required skill sets for different jobs. A convenience sample of participant farms was recruited through the Pork Producers and the PDPW. Worksite consultants were trained in the use of the functional job assessment data collection tool through hands-on field training at several initial sites. The recruited dairies and pork production sites were visited by worksite consultants in Wisconsin (dairy) and Minnesota (pork). The consultants conducted functional job assessments on the tasks in the pork and dairy worksites. This information was documented first in Microsoft Word documents and then manually entered into a REDCap database [13]. A subset from REDCap is now used as the backend dataset for the SafeReturnToWork.org prototype. The design of the database consists of linked tables containing the data elements captured in the job assessments. 
The prototype application now uses the data to compile which suggested tests should be conducted to determine if the worker is capable of performing these specific work tasks, taking into account their physical limitations.

As a stakeholder-engaged project, interviews $(n=6)$ with farm owners/managers, and focus groups $(n=5)$ with farmworkers $(n=35)$ were conducted in order to gather feasibility- and usability-related data, which informed the software development team. The data collection methods and results from those interviews and focus groups are the topic of another manuscript. [14]

\section{Results}

The task list information was compiled and inserted into a web-based software prototype application. The software has several key components: (1) a database of functional job profiles, (2) a clinician interface and input form, and (3) customized return-to-work output sheets for farm owners and their injured workers available in English or Spanish.

\subsection{Complexity and Variation of Farm Tasks}

A total of 192 farm tasks were identified, measured, collected, and entered into the system. A sample of the data is displayed in Table 1. Initial project design proposed an analysis of injury/degree categories (five injury types $x$ two degrees of impairment) and matching job assemblages.

Table 1. Sample of data contained in the database.

\begin{tabular}{|c|c|c|}
\hline Job Title & Task Name & Equipment \\
\hline Calf feed & $\begin{array}{l}\text { Obtain cow milk from bulk tank or } \\
\text { pipeline; fill containers }\end{array}$ & $\begin{array}{l}\text { Clamps, pipes, levers, faucets; large tank on back of } \\
\text { trailer or 'gator'; usually done inside 'milkhouse' or } \\
\text { specified building }\end{array}$ \\
\hline Calf feed & $\begin{array}{l}\text { Esophageal (tube) feed newborns or ill } \\
\text { calves }\end{array}$ & Esophageal tube, milk 'bottle'; calf inside hutch or pen \\
\hline Calf feed & $\begin{array}{l}\text { Mix milk replacer powder with water in } \\
\text { pails }\end{array}$ & $\begin{array}{l}50 \mathrm{lb} \text { bags of milk replacer; } 5 \text { gallon pail, whisk; usually } \\
\text { done in 'milkhouse' or specified building }\end{array}$ \\
\hline Calf feed & Transport milk and/or water to calves & Gator, wagon or cart; pails (full and empty) \\
\hline Calf feed & Clean pails, bottles and equipment & Sink, spray hose, bottles of cleaning agents, scrub brush \\
\hline Calf feed & Use fork & $\begin{array}{l}\text { Wheelbarrow, possibly skid-steer to clean; may tip } \\
\text { hutches up }\end{array}$ \\
\hline Calf feed & Feed calves milk or water from pails & $\begin{array}{l}\text { Large container with faucet or large pail, calf pails; pail } \\
\text { holders inside hutch; calf typically in individual hutch; } \\
\text { can be in pen with others on some farms }\end{array}$ \\
\hline Calf feed & $\begin{array}{l}\text { Feed grain and hay-placing into pails or } \\
\text { troughs }\end{array}$ & $\begin{array}{l}\text { Pails, gates, manger, can use wheelbarrow, wagon, or } \\
\text { cart, forks }\end{array}$ \\
\hline Calf feed & Feed newborns via nipple bottles & $\begin{array}{l}\text { Large container with faucet or large pail, calf nipple } \\
\text { bottle; calf typically in individual hutch; can be in pen } \\
\text { with others on some farms }\end{array}$ \\
\hline Cow pusher & Clean aisles and floor in stalls and parlor & Shovel, fork, wheelbarrow, cart \\
\hline Cow pusher & Direct cows to milking area & Gate controls \\
\hline
\end{tabular}

Assemblages appearing to be non-productive, disruptive to operations, or unfeasible were to be reworked. Alternative assemblages were to be developed that might work better in the given workplace. Prior to the project, it was hypothesized that a given assemblage may or may not be feasible in a workplace, depending on the size of operations or differences in the animal, manure, and feed management practices. This complexity was confirmed. There is much variation between farming operations. This hurdle made it nearly impossible to match and combine assemblages in any meaningful and useful way. Interviews with farmers and workers also confirmed that the system need not compile individual tasks into complete assemblages to make a job, rather to just display tasks as 
options that an injured employee may still be able to perform on the job, and then let the farm employer or manager make the determination on where and when the worker can be of use within the operation.

The initial modeled jobs assisted in identifying characteristics of the workplace that could be used to match the assemblage to the operation. These workplace characteristics included seasonality (spring, summer, fall, winter) and milking systems (stanchion, tie stall, parlor, robotic). A third group of factors was discussed during numerous team meetings, but these factors could not be incorporated into the algorithms for the final computer program.

\subsection{Ergonomic Data Collection}

The digital media were labeled and stored in an electronic database developed using a locally housed copy of the REDCap application [13]. Physical and occupational therapists collected detailed functional job and task measurements from 32 implement dealers, dairies, and pork farms (Figure 1). To characterize the ergonomic components of various farm tasks, physical and occupational therapists analyzed photographs, videos, and information from farmers, farmworkers, and implement dealers.

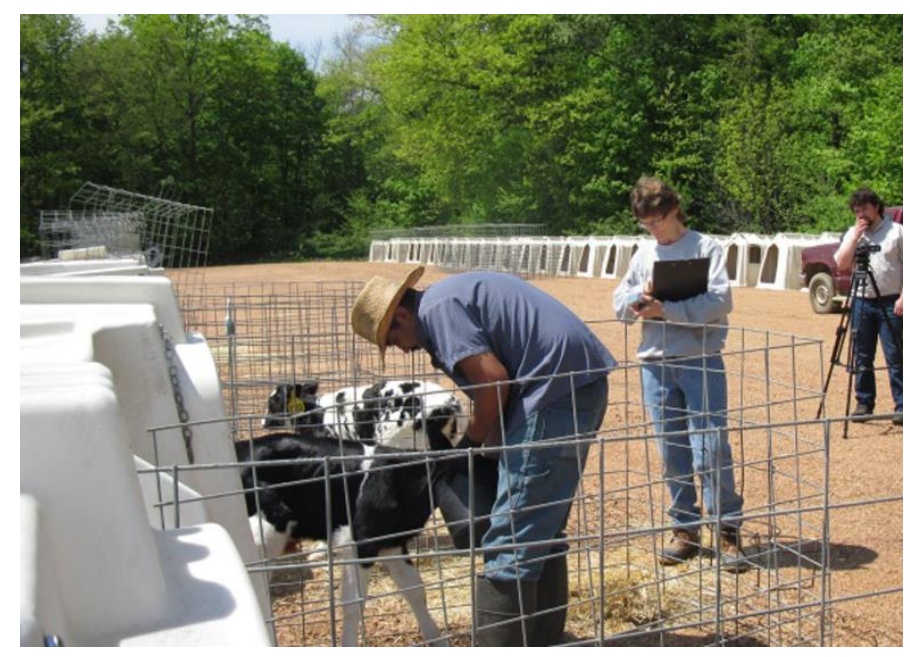

Figure 1. Occupational therapist collecting field data.

Their results were then transferred to a paper version of the collection form. Narrative data (descriptions of tasks and activities) almost always accompanied the structured data (heights, weights, etc.). Noted throughout the project by the information technology team, narrative data would be of little use in the software application. Thus, iterations of the collection form incrementally moved toward a more structured approach, with less free-text space for data collection. In total, 23 versions of the form were field-tested before a final version was found acceptable. An electronic form was later created using REDCap. This system provided an input form and electronic storage for the project. It was designated to store all field data collected by the occupational therapists. A subset of that data was later used to populate the backend dataset of the SafeReturnToWork.org assessment tool.

The process of moving data from the collection form into a normalized database structure involved identifying the inherent structure of the data collected and how different aspects of the form related to one another. As previously noted, occupational therapists tended to collect vast amounts of qualitative data. This presented challenges when trying to identify shared aspects and structure for storage in a database. This problem was addressed by identifying common physical demands that each farm task required, the personal protective equipment required to perform the task, and the amount of weight required (if any) in any tasks involving lifting or pushing. Each task's physical demands were mapped to corresponding limitations, which the physician fills out when using the application.

It was found that some aspects of the data were simply not needed for the algorithmic determination of performable tasks in the application. For example, the duration of the task was not relevant, because 
many farm tasks can be performed anywhere from $15 \mathrm{~min}$ to 8 or more hours. Thus, the physician would be the one to decide how long an injured worker could perform a task.

\subsection{Algorithmic Use of Collected Data}

The team discovered that it is difficult to create an application to confirm whether an injured worker can perform a given farm task. It was decided to pivot the approach to something much clearer that would still provide valuable decision support for the physician. The algorithm now runs in three primary steps for a given task. First, it determines if the injuries the worker has sustained make it impossible for them to perform the task. It does this by comparing any limitations set to $0 \%$ (meaning the worker can never do this) to their corresponding physical demands for the task. For example, if the task requires lifting and carrying, but the physician has indicated that the worker cannot lift nor carry, then the task can be eliminated.

Secondly, the algorithm checks to see if there are no matching limitations for the physical demands of a given task. This indicates that the worker has sustained an injury that does not appear to inhibit them from performing this task at all. Tasks that pass this round are considered possible candidates for the worker.

Finally, the algorithm goes through the "grey area" tasks—tasks that could potentially be done by the worker but not to their full capacity. The algorithm evaluates each limitation provided by the physician and the time restraints that have been set, then it checks against the physical demands required for the task. With these pieces of data, a rough estimate can be given of a time range in which the injured worker can perform this task. Tasks that have a higher result (meaning they can do them for a longer period) are the best candidates from this category. An internal threshold is set as a bottom line - tasks that fall below this threshold are bad candidates and are eliminated entirely.

\subsection{Integration with an Electronic Health Record}

The application's core logic - the algorithm that determines if an injured worker can perform a task - can be extracted outside of the application and hosted independently. This makes integration with an electronic health record simpler. As long as the data are provided in the right structure, the algorithm can run over it and return meaningful results. Tasks also do not need to be limited to agriculture. As long as the task's physical demands are identified, the algorithm can run against them and generate a result set. It can also be configured to not store any information about the result, which reduces any security concerns and gives it greater flexibility to be used in the field over insecure networks. Yet, there is significant variability in healthcare information systems' structures, frameworks, and leadership. Implementation and integration of any new system into an EHR requires a much more detailed description, outside the scope of this paper.

\section{Discussion}

Large animal husbandry is among the most dangerous jobs in the United States. Agricultural economics is driving consolidation, and as farms grow from family operations to employers of hired labor, farmers become managers. As managers, farmers must partner with primary care clinicians to safely return injured workers/patients to productivity. The cost of waiting for an injured worker's full recovery is impractically high. Neither farmers nor the vast majority of primary care clinicians have adequate preparation for this partnership to be fully effective. The Safe Return to Work project is designed to provide an assistive interface for this partnership. The Safe Return to Work was designed to provide clinicians with an intuitive portal to input worker/patient limitations and illustrate feedback as to matching work tasks, and to provide farmers with illustrated task lists compatible with the worker/patient's capabilities. 


\section{Limitations}

This project had several limitations. First, the ergonomic data was collected from a finite number of farms located in the Upper Midwest of the United States. These farms may be representative of the dairies across the region, but may not accurately reflect the dairying practices of all operations across the nation or the world. Furthermore, dairies across the region were also quite different in operational practices and available equipment, depending on the size and scope of the operation [15]. For example, a smaller farm milking less than 75 dairy cows may be more likely to maintain a stanchion or tie-stall operation for milking via pipeline, whereas farms with several hundred cows or more are likely to have implemented some type of parlor system, where milking tasks for workers are ergonomically much different [15-17].

Secondly, the software outputs (suggested farm tasks for an injured worker) are based upon the assumption that the inputs (ergonomic data and patient limitations) are appropriately gathered and entered. Furthermore, it is assumed that the clinician using the system has a basic understanding of the tasks that will be suggested to the injured worker, although, this is not always the case.

Thirdly, the adoption of this type of software in a clinical setting is almost entirely bound to the motivation of the clinician to employ it. While the software can provide value to the clinician, the patient, the insurer, and the employer, there is little incentive for the clinician to initiate or complete the workflows of the software, adding to a potentially already busy schedule and limited time with individual patients.

Lastly, disseminating this type of software outside the developers' own healthcare system would be a significant challenge. Short of partnering with an electronic health record company (e.g., Epic or Cerner), the software would be very difficult to employ in any integrated fashion with another health system's electronic health record, or to even break into the workflows of rural clinicians who may only see a handful of injured farmworkers each year.

\section{Conclusions}

This paper describes the development of the database and algorithm for the Safe Return to Work project. The iterative process of transforming the narrative observational process of the field occupational therapists into quantitative input amenable to algorithmic manipulation was the greatest challenge. The experience with real farm environments pointed out the challenge of providing farmers with useable light duty job assemblies. Consequently, farmers were provided with a menu of viable tasks for their own assemblage. Moving forward, it is recognized that the concept, as well as the algorithm and background database, have applicability in non-agricultural work environments and could be incorporated into electronic medical record systems compatible with the Health Insurance Portability and Accountability Act (HIPAA) privacy requirements. Finally, there may be potential for integration, as a stand-alone system, into the operations of agricultural employers (farmers and farm managers) and workers' compensation insurance companies.

Author Contributions: B.W. managed the project, including data collection, and led the drafting of the manuscript. W.R. led database design, web application and user interface development. M.K. conceived of the study and participated in the project design and coordination, and helped to draft the manuscript. All authors contributed to the interpretation of data, drafting the manuscript, and revising it critically for important intellectual content, and all agree to be accountable for all aspects of the work in ensuring that questions related to the accuracy or integrity of any part of the work are appropriately investigated and resolved.

Funding: This work was supported by the Marshfield Clinic Research Institute, the National Farm Medicine Center, and the Upper Midwest Agricultural Safety and Health Center, as part of cooperative agreement U54OH010170 from the National Institute for Occupational Safety and Health, U.S. Centers for Disease Control and Prevention.

Acknowledgments: The authors would like to thank all the participating farms and implement dealers for their support of the project and willingness to allow data collection on their operations. The authors also thank all the members of the study team and support staff for their dedication to the project. The authors also thank Marie Fleisner from the National Farm Medicine Center for assistance with editing the manuscript.

Conflicts of Interest: The authors declare no conflict of interest. 


\section{References}

1. Leigh, J.; McCurdy, S.; Schenker, M. Costs of Occupational Injuries in Agriculture. Public Health Rep. 2001, 116, 235-248. [CrossRef]

2. United States Department of Labor (USDL); Bureau of Labor Statistics (BLS). National Census of Fatal Occupational Injuries in 2015. Available online: https://www.bls.gov/news.release/pdf/cfoi.pdf (accessed on 9 May 2017).

3. Karttunen, J.P.; Rautiainen, R.H. Characteristics of and risk factors for compensated occupational injury and disease claims in dairy farmers: A case-control study. J. Agric. Saf. Health 2013, 19, 191-206. [PubMed]

4. United States Department of Agriculture, National Agricultural Statistics Service. 2016 Wisconsin Agricultural Statistics. Available online: https://www.nass.usda.gov/Statistics_by_State/Wisconsin/Publications/Annual_ Statistical_Bulletin/2016AgStats_web.pdf (accessed on 9 May 2017).

5. Liebman, A.; Juarez-Carrillo, P.; Reyes, I.; Keifer, M. Immigrant dairy workers' perceptions of health and safety on the farm in America's Heartland. Am. J. Ind. Med. 2016, 59, 227-235. [CrossRef] [PubMed]

6. Blazek, J.; Barnett, K.; Wagner, T.; Vanderlin, J. Paper No. 3: Human Resource Characteristics and Challenges for Wisconsin Farms; FARM Team, UW-Extension: Madison, WI, USA, 2013.

7. Hagevoort, G.R.; Douphrate, D.; Reynolds, S.J. A review of health and safety leadership and managerial practices on modern dairy farms. J. Agromed. 2013, 18, 265-273. [CrossRef] [PubMed]

8. Keifer, M. High Time for HITEC to Include Occupational Information in the Electronic Health Record. J. Agromed. 2015, 20, 395-397. [CrossRef] [PubMed]

9. Jurisic, M.; Bean, M.; Harbaugh, J.; Cloeren, M.; Hardy, S.; Liu, H.; Nelson, C.; Christian, J. The personal physician's role in helping patients with medical conditions stay at work or return to work. J. Occup. Environ. Med. 2017, 59, e125-e131. [CrossRef] [PubMed]

10. Kilgour, E.; Kosny, A.; McKenzie, D.; Collie, A. Healing or harming? Healthcare provider interactions with injured workers and insurers in workers' compensation systems. J. Occup. Rehabil. 2015, 25, 220-239. [CrossRef] [PubMed]

11. Hallden, J. The original intent of workers' compensation: A team approach. Work 2014, 48, 435-459. [PubMed]

12. Safe Return to Work. Available online: www.SafeReturnToWork.org (accessed on 9 May 2017).

13. Harris, P.A.; Taylor, R.; Thielke, R.; Payne, J.; Gonzalez, N.; Conde, J.G. Research electronic data capture (REDCap)-A metadata-driven methodology and workflow process for providing translational research informatics support. J. Biomed. Inform. 2009, 42, 377-381. [CrossRef] [PubMed]

14. Weichelt, B.; Bendixsen, C.; Keifer, M. Farm Owners and Workers as Key Informants in User-Centered Occupational Health Prototype Development: A Stakeholder-Engaged Project. J. Med. Internet Res. 2019, 21, e9711. [CrossRef] [PubMed]

15. Douphrate, D.I.; Hagevoort, G.R.; Nonnenmann, M.W.; Lunner Kolstrup, C.; Reynolds, S.J.; Jakob, M.; Kinsel, M. The dairy industry: A brief description of production practices, trends, and farm characteristics around the world. J. Agromed. 2013, 18, 187-197. [CrossRef] [PubMed]

16. Kirkhorn, S.R.; Earle-Richardson, G.; Banks, R.J. Ergonomic risks and musculoskeletal disorders in production agriculture: Recommendations for effective research to practice. J. Agromed. 2010, 15, 281-299. [CrossRef] [PubMed]

17. Kolstrup, C.; Stal, M.; Pinzke, S.; Lundqvist, P. Ache, pain, and discomfort: The reward for working with many cows and sows? J. Agromed. 2006, 11, 45-56. [CrossRef] [PubMed]

(C) 2019 by the authors. Licensee MDPI, Basel, Switzerland. This article is an open access article distributed under the terms and conditions of the Creative Commons Attribution (CC BY) license (http://creativecommons.org/licenses/by/4.0/). 